\title{
Catalyst Coatings for Microstructure Reactors
}

\author{
Katja Haas-Santo*, Oliver Görke, Peter Pfeifer, and Klaus Schubert
}

\begin{abstract}
Catalytic active coatings for microchannels have been developed for metallic microstructure reactors in heterogeneous catalyzed gas phase reactions. To enhance the inner surface of microchannel reactors, porous metal oxide coatings have been made by various deposition techniques such as sol-gel processes, anodic oxidation, and deposition of nanoparticles. The ceramic thin films have been developed as supports for catalytically active components like precious metals or as catalyst themselves. In an aluminum microstructure reactor the walls of the micro channels of one passage was successfully coated with a porous alumina layer by a modified anodic oxidation method. Moreover, microchannels of microstructure reactors were successfully coated with $\mathrm{SiO}_{2}, \mathrm{Al}_{2} \mathrm{O}_{3}$ and $\mathrm{TiO}_{2}$ by the sol-gel process. First promising results have been obtained from depositing oxide nanoparticles $\left(\mathrm{ZnO}, \mathrm{CuO}\right.$ and $\mathrm{Al}_{2} \mathrm{O}_{3}$ ) by washcoat or electrophoretic deposition methods.
\end{abstract}

Keywords: Anodic oxidation · Catalytic coating $\cdot$ Microstructure reactor $\cdot$ Nanoparticles $\cdot$ Sol-gel

\section{Introduction}

Microstructured components, such as micro heat exchangers, micromixers, and microstructured reactors (Fig. 1), are especially suited for use in thermal and chemical process engineering, where high thermal and/or mass transfer rates are required and small dimensions are advantageous. Overall heat transfer coefficients of up to $1700 \mathrm{~W} / \mathrm{m}^{2} \cdot \mathrm{K}$ have been measured for gasto-gas [1] and up to $54000 \mathrm{~W} / \mathrm{m}^{2} \cdot \mathrm{K}$ for water-to-water heat transfer [2][3]. Their vacuum tightness, the high-pressure stability of several hundred bar, and the flame-arresting properties of the fine microchannels, for instance, even allow highly exothermic reactions with high educt concentrations in undiluted media in the explosion range to be performed without the risk of thermal runaway [4][5].

\footnotetext{
${ }^{{ }^{*} C o r r e s p o n d e n c e}$ : Dr. K. Haas-Santo Forschungszentrum Karlsruhe

Institute for Micro Process Engineering Postfach 3620

D-76021 Karlsruhe, Germany

Tel.: +497247826655

Fax: +49724782 3186

E-Mail: katja.haas-santo@imvt.fzk.de www.fzk.de/imvt
}

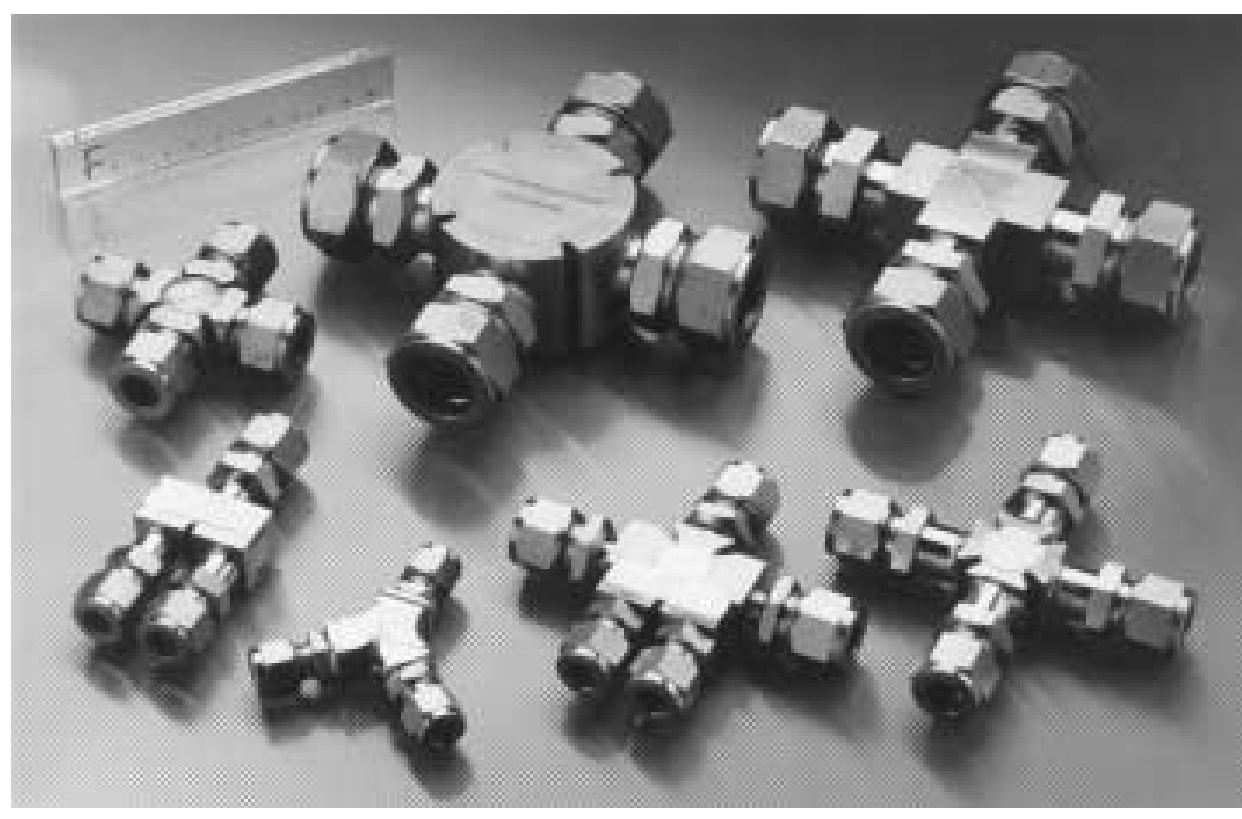

Fig. 1. Microstructured components, such as micro heat exchangers, micromixers, and microstructured reactors, as designed and fabricated by the Forschungszentrum Karlsruhe.

The microchannel reactors are made of mechanically microstructured metal foils of e.g. stainless steel, hastelloy, aluminum, copper, palladium, silver, and others. A reactor is assembled from individual metal sheets with micromachined channels having cross sections in the range of 50 to $300 \mu \mathrm{m}$. These metal foils are stacked and diffusion bonded, thus resulting in an es- sentially monolithic assembly whose channels are vacuum-tight and may handle pressures of up to several 100 bars. The core is adapted to a housing with standard tube connections by electron beam welding [4].

Microstructured components may also be applied in heterogeneously catalyzed gas phase reactions. For this, the reactor can be entirely made of a catalytically active 
material, e.g. silver, palladium or rhodium [6]. But for some heterogeneously catalyzed reactions, the inner geometric surface area is too small to fix a sufficient number of 'active centers'. It is therefore necessary to develop coatings with a large surface area on microstructured metal carrier materials for subsequent impregnation with catalytically active substances, e.g. noble metals.

There are several requirements porous oxide coatings have to fulfill for catalytic applications in microchannel devices: A coating should provide a large surface area, which means that it must have a high porosity so that many active centers are created when wet impregnated with a catalytically active species. Furthermore, mechanical stability and adhesion to the metallic support are crucial, because detachment of small particles can easily lead to blocking due to the small dimensions of the microchannels.

Several techniques have been described for coating the inner surface of microchannel reactors with porous oxides:

- anodic oxidation of aluminum [7][8],

- sol-gel process [9],

- washcoating of nanoparticles [10][11]

- electrophoretic deposition of nanoparticles [11]

- chemical vapor deposition [5].

\section{Methods}

One method to realize a catalytically active porous coating on microstructured metal foils is the anodic oxidation of aluminum foils and subsequent immobilization of the catalytically active species. It is possible to generate adherent $\mathrm{Al}_{2} \mathrm{O}_{3}$ layers of variable thickness with a regular mesopore system [12]. Having selected appropriate electrolyte solution and bath parameters and duration of the anodic oxidation, pore widths ranging from 10 to $100 \mathrm{~nm}$ with small radius distributions can be achieved. The pore length more or less corresponds to the thickness of the oxide layer. By using sulfuric acid as electrolyte, the geometric surface area of a microchannel may be enlarged by factors of up to 100 per micrometer layer thickness [8][13].

The first microchannel reactors based on such coatings have been developed in collaboration with the Technical University of Chemnitz [7]. By piling up the microstructured and catalytically activated foils, a microstructured reactor with a stack of foils with microchannels was formed.

With these applications, the combination of the regular pore system together with the defined residence time distribution in the microchannels was proven to be advantageous to attain high selectivities for a desired product.

However, the ceramic coating does not allow the foil stack to be joined by diffusion welding, which is essential to obtain vacuum-tight and pressure-resistant microchannel systems with two separated fluid passages. Due to this fact, only aluminum microchannel reactors consisting of foil stacks in a honeycomb arrangement and with only one fluid passage have been manufactured up to now.

So far, anodic oxidation was not considered to be feasible in the fine channel structures of microstructured reactors, as penetration of the electric flux lines into the depth of the structure appeared impossible. However, our own experiments have demonstrated that an appropriate combination of electrode arrangement and electrolyte flow rate allows for the complete anodic oxidation of microchannels inside an already manufactured aluminum micro-channel reactor with two passages [8].

Another promising method of applying oxide layers onto the walls of microchannels is the sol-gel technology. It has the advantage of producing a wide variety of possible compositions and tailored porosity and surface texture. These properties can be changed by varying the composition and treatment procedure of the sols [14]. One great advantage is that it is possible to generate ceramic coatings of mixed metal oxides as support or as catalyst themselves.

The sol-gel process is an established method for the production of particulate bulk material as porous support for catalysts as well as dense thin film coatings having a low porosity on glasses [15]. Most important is the combination of the porosity of the bulk material with the good adhesion and mechanical stability of dense thin films as it is essential that the porous oxide films adhere to the surface. In the sol-gel process for the production of metal oxides the colloidal sols can be prepared by a number of different methods such as reactions of aqueous solutions of metal salts or hydrolysis and polycondensation of metal alkoxides to form oxides. The latter is the most versatile and has been investigated extensively [16]. The process of hydrolysis allows different metal precursors to be mixed when preparing the sol.

Partially hydrolyzed metal precursors form gels during subsequent polycondensation reactions. These reactions can be accelerated via acid or basic catalysis. The metal substrates can be coated for example by dip-coating so that thin gel films are formed. The wet gel films are converted into porous oxides by drying, followed by heat treatment. Although the chemical reaction and the process first appear simple, the influence of the various process parameters on the properties of the coating is complex. These parameters include the choice of solvent, whether acid or base catalysis is employed, the nature of the used alkoxide, and the use of stabilizing agents. Therefore, these influences on the properties of the oxide coating have to be taken into account to obtain thin porous coatings with good adhesive properties on metal supports. So far coatings based on alumina, silica, and titanium oxide have been developed as supports for catalytically active components. Thin film coating was accomplished by dip coating using microstructured thin metal foil as support [9].

A different approach is the development of coatings based on immobilized and sintered nanoparticles. The deposition of nanoparticles has the distinct advantage that metal oxide catalysts themselves can be deposited onto the walls of the channel. The subsequent impregnation of the support is not really necessary and the method is more versatile. The deposition of the nanoparticles can be achieved by two different methods:

The first method is to washcoat the surface of the metal foils with dispersed particles. The dispersion of catalytically active materials in a carrier structure is achieved by an intense mixture of commercially available nanoparticles of the catalyst and the promoter or carrier material. The mixture is immobilized on the microchannel walls and sintered. The sintering process influences the pore structure and the formation of intermetallic phases which, in some cases, are responsible for the catalytic behavior of the coating. The advantage of this method is that, depending on the procedure, no additional impregnation step is necessary after immobilization of the nanoparticles. The pore structure of the coating is dominated by macropores and depends on the type of the nanoparticles and the thermal treatment procedure [10].

Electrophoretic deposition (EPD) of nanoparticles represents the second method for the deposition of oxide layers made of nanoparticles such as $\mathrm{Al}_{2} \mathrm{O}_{3}, \mathrm{ZnO}, \mathrm{CeO}_{2}$, from colloidal solutions in microchannels. Here, the mass and properties of the oxide layer in the microchannels can be influenced specifically by the chosen parameters (composition and $\mathrm{pH}$ value, voltage density, duration). First studies have been performed with regard to the electrophoretic deposition of aluminum oxide nanoparticles in microchannels. For this purpose, stable suspensions of $\mathrm{Al}_{2} \mathrm{O}_{3}$ nanoparticles in aqueous oxalic acid glycerol solutions 
with varying composition are produced [11].

The chemical vapor deposition (CVD) process is a valuable tool to obtain porous ceramic coatings on the inner walls of a microchannel system. A catalytic microreactor equipped with an alumina layer which was deposited by atmospheric pressure CVD and with platinum as active component was developed in collaboration with the Max Planck Institute in Mülheim [5]. The coating consists of $\gamma$-alumina and has a surface enhancement factor of about 100 with a layer thickness of about $10 \mu \mathrm{m}$. The microreactor is able to convert explosive $\mathrm{H}_{2} / \mathrm{O}_{2}$ mixtures safely into water.

\section{Results}

The oxide layers made by the different processes were inspected by scanning electron microscopy using cross sections of the samples. Surface characterization was done by nitrogen physisorption using the BET method. Due to the formation of pores in the oxide layer, the surface area increased. For comparison a surface magnification factor was defined as the quotient of surface area determined by physisorption by the BET method and geometrical surface area of the microchannels.

Anodic oxidation was carried out using an AlMg alloy (3\% $\mathrm{Mg})$ as material. The microstructured foils were $300 \mu \mathrm{m}$ thick. The microchannels were $50 \times 50 \mu \mathrm{m}$, $100 \times 100 \mu \mathrm{m}$, and $200 \times 200 \mu \mathrm{m}$ in dimension. In addition, a completely manufactured microstructured $\mathrm{AlMg}$ reactor was used for anodic oxidation of the microchannels of one passage (channel geometry $100 \times 200 \mu \mathrm{m})$.

Anodic oxidation took place at constant direct voltage and constant temperature. The electrolyte was 1.5 wt.\% oxalic acid. The electrolyte was pumped through the microstructured foils fixed in a holding unit or through the microchannels of the microstructure reactor. Aluminum wires at the inlet and outlet of the channels served as cathodes. The voltage applied was $50 \mathrm{~V}$. As other experimental conditions, an electrolyte temperature of $12{ }^{\circ} \mathrm{C}$, an electrode distance from the $\mathrm{Al}$ body of $10 \mathrm{~mm}$, and an electrolyte flow of $30 \mathrm{l} / \mathrm{h}$ were set. Following anodic oxidation, the specimens were rinsed with demineralized water and dried at $500{ }^{\circ} \mathrm{C}$.

After performing the anodic oxidation cross sections of the anodically oxidized microchannel reactors were made and the layer thickness of the aluminum oxide films was studied and measured in transverse sections. Fig. 2 shows the diagonal crossec- tion of a crossflow reactor of $1 \mathrm{~cm}^{3}$ volume after $6 \mathrm{~h}$ of anodic oxidation. It can be seen that the walls of all microchannels of one passage are covered by an adherent uniform aluminum oxide layer whereas the second passage remains unchanged. Cross sections at various positions along a microchannel passage show that the coating is homogeneous over the channel length (Fig. 3). Layer thicknesses are the same at any point along the reaction channel.

The distance of both cathodes from the microstructured body, which ranges between 5 and $30 \mathrm{~mm}$, hardly affects layer formation. The geometry parameters of the microstructure, such as the length and cross section of the microchannels, are of far greater influence (Fig. 4). For instance, smaller microchannels appear to inhibit anodic oxidation. At channel lengths of $15 \mathrm{~mm}$ and channel diameters of $200 \mu \mathrm{m}$, layer thicknesses of $7 \mu \mathrm{m}$ result after $6 \mathrm{~h}$. At channel diameters of $50 \mu \mathrm{m}$, however, layer thicknesses of only $4 \mu \mathrm{m}$ are obtained. Larger channel lengths also cause the layer thickness to be reduced. A channel length of $40 \mathrm{~mm}$ results in a $3 \mu \mathrm{m}$ thick layer only.

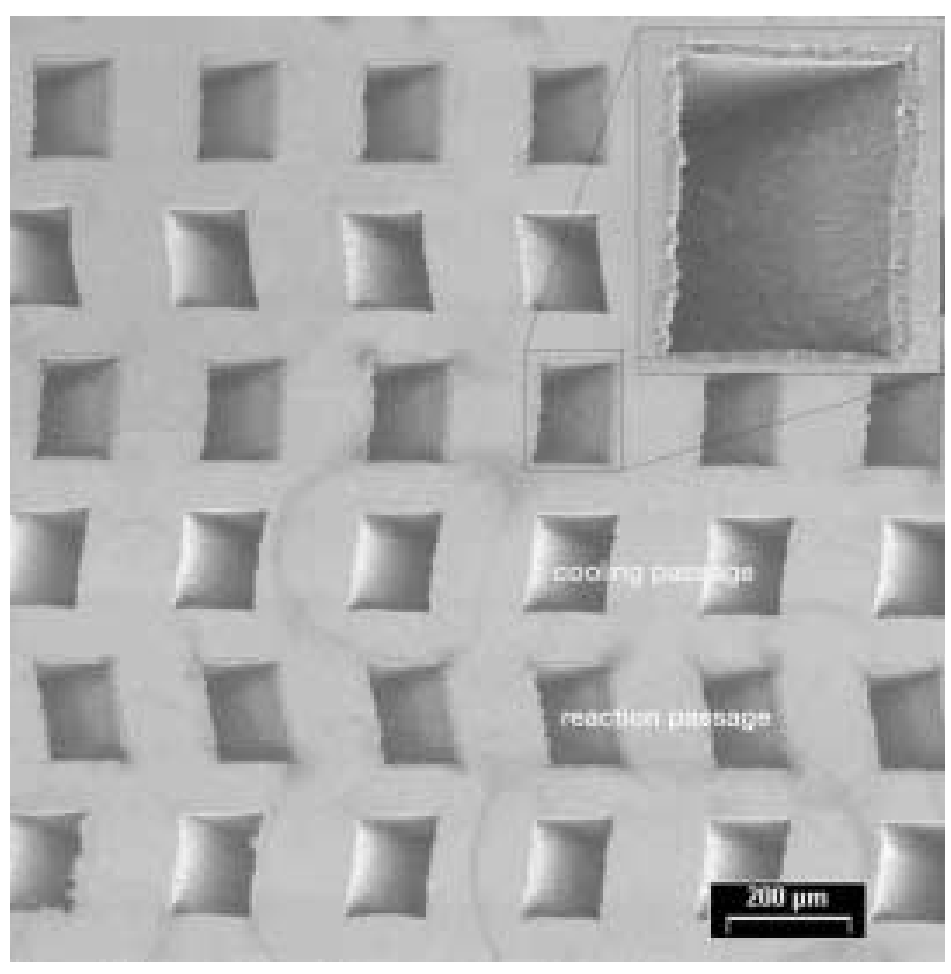

Fig. 2. SEM of a diagonal cross section of a diffusion-welded and then anodically oxidized microstructured reactor made of aluminum (crossflow reactor). The channels of one passage are anodically oxidized, the second passage is original.

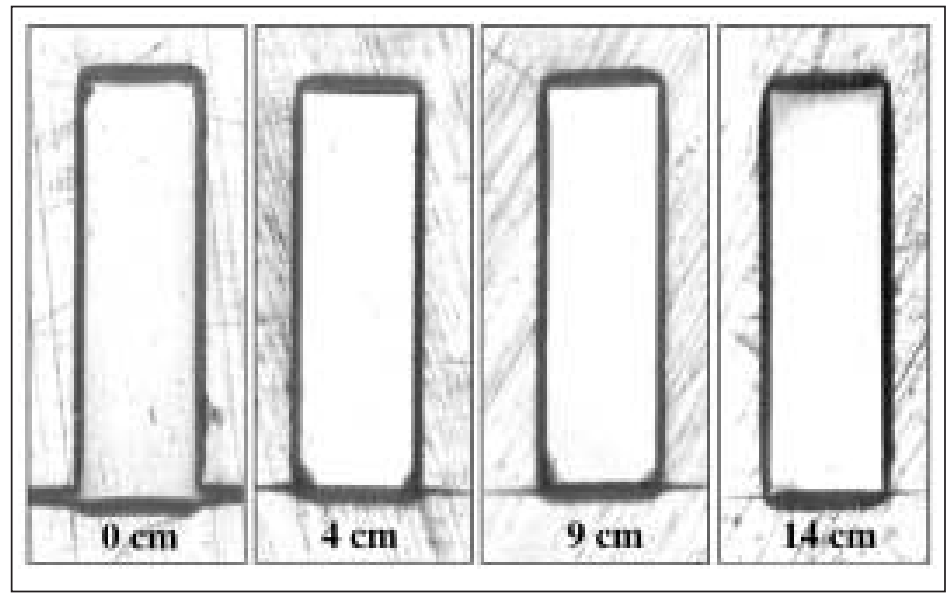

Fig. 3. Transverse sections at various positions along an anodically oxidized microchannel (material: AlMg, anodic oxidation conditions: oxalic acid $1.5 \mathrm{wt} . \%, \mathrm{U}=50 \mathrm{~V} ; \mathrm{t}=4 \mathrm{~h} ; \mathrm{T}=12{ }^{\circ} \mathrm{C}$; electrode distance $10 \mathrm{~mm}$ ). 


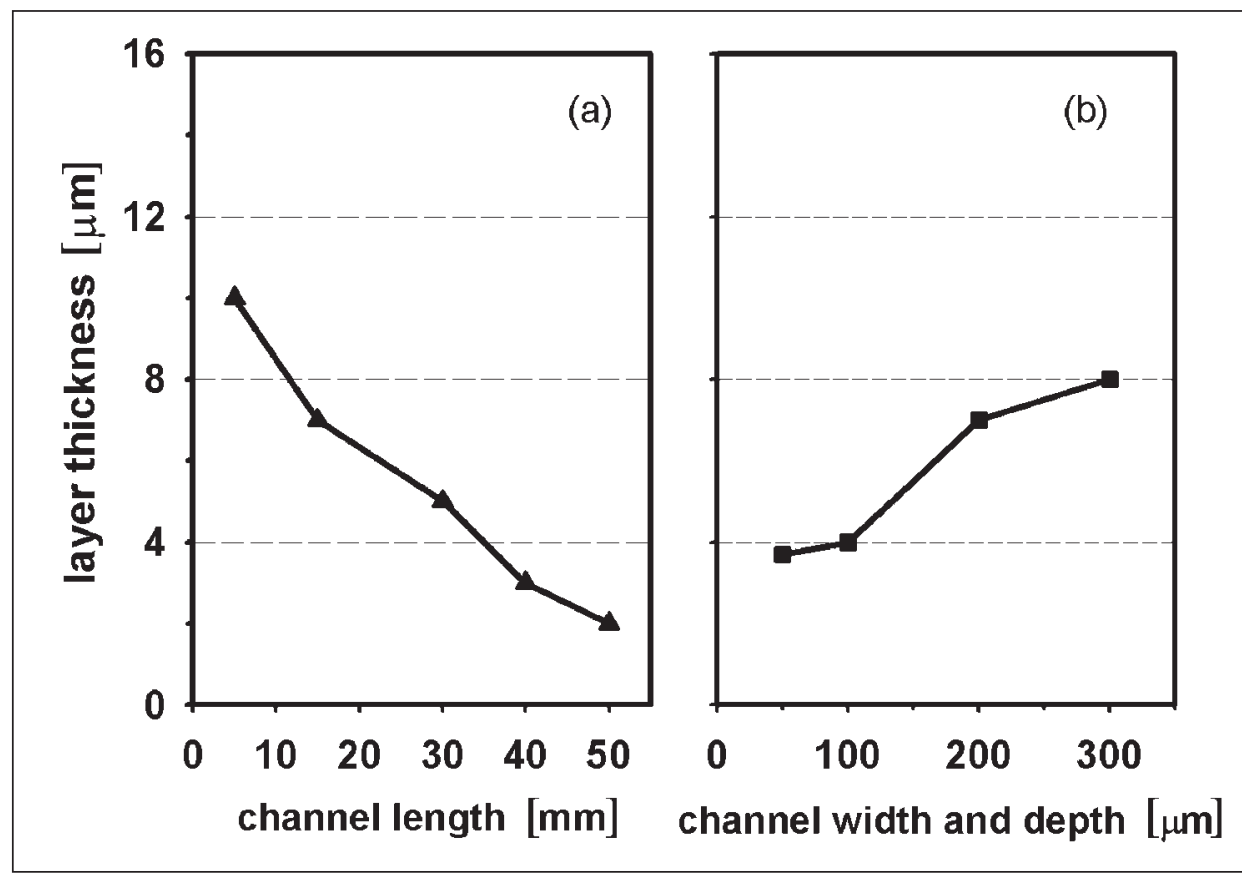

Fig. 4. Thickness of the aluminum oxide layer as a function of channel geometry and channel length (material: AIMg: anodic oxidation conditions: Oxalic acid 1.5 wt. $\%, U=50 \mathrm{~V} ; \mathrm{T}=12{ }^{\circ} \mathrm{C}$; electrode distance $10 \mathrm{~mm}$, (a) channel width and height $200 \mu \mathrm{m}$; (b) channel length $15 \mathrm{~mm}$ ). coatings made of aluminum sec.-butylate $\left(\mathrm{F}=430 \mathrm{~m}^{2} / \mathrm{m}^{2}\right)$ and the lowest for titanium oxide coatings (Table). When aluminum and titanium precursors were mixed in equimolar amounts the surface was only slightly enhanced in comparison to pure titanium oxide, $74 \mathrm{~m}^{2} / \mathrm{m}^{2}$ and $100 \mathrm{~m}^{2} / \mathrm{m}^{2}$, respectively. When titanium is replaced by silicon the surface area rises, resulting in a surface enhancement factor of 193. With the mixtures of $\mathrm{SiO}_{2}$ and $\mathrm{Al}_{2} \mathrm{O}_{3}$ the resulting surface area was found to be similar to that of pure $\mathrm{SiO}_{2}$ or even lower. Thermal treatment of the $\mathrm{Al}_{2} \mathrm{O}_{3}$ coatings has an enormous influence on resulting surface enhancement factors. The highest specific surface area for $\mathrm{Al}_{2} \mathrm{O}_{3}$ coatings were obtained at a calcination temperature of $500{ }^{\circ} \mathrm{C}\left(\mathrm{F}=430 \mathrm{~m}^{2} / \mathrm{m}^{2}\right)$. Decreasing values were observed when the temperature was increased $\left(\mathrm{F}=30 \mathrm{~m}^{2} / \mathrm{m}^{2}\right.$ for $\left.\mathrm{T}=800^{\circ} \mathrm{C}\right)$ or decreased $\left(\mathrm{F}=3 \mathrm{~m}^{2} / \mathrm{m}^{2}\right.$ for $\left.\mathrm{T}=400{ }^{\circ} \mathrm{C}\right)$. A gel film calcined at $800{ }^{\circ} \mathrm{C}$ can transform into an $\alpha$-alumina and porosity decreases due to sintering of the alumina layer [19].
Like the coating of open surfaces, layer thickness increases with the duration of anodic oxidation. During the first $4 \mathrm{~h}$, the layer grows by about $4 \mu \mathrm{m} / \mathrm{h}$. Then the growth rate drops. Compared to this, layer thickness of an open surface grows more rapidly. After $3 \mathrm{~h}$, a layer thickness of $16 \mu \mathrm{m}$ is reached instead of $12 \mu \mathrm{m}$ in the channel [8]. The microchannels inhibit anodic oxidation, but do not prevent it. Hence, anodic oxidation may well be applied for the production of aluminum oxide layers in microchannels of completely manufactured microstructured reactors. In these experiments surface enhancement factors of up to $400 \mathrm{~m}^{2} / \mathrm{m}^{2}$ (film thickness $=12 \mu \mathrm{m}$ ) were reached, thus leading to a high surface area for heterogeneous catalyzed reaction like the complete combustion of small amounts hydrocarbons in air [17] and the controlled oxidation of explosive gas mixtures of hydrogen and air [8].

The sol-gel coating was obtained by a simple dip-coating process. The microstructured reactors were put up such that the channels to be coated were in a vertical position. Then, the sol was fed into the channels with wetting of the entire channel surface being ensured. After this, excessive sol was blown out with a small air flow. The coated bodies were then dried at $80{ }^{\circ} \mathrm{C}$ and subjected to calcination at $500{ }^{\circ} \mathrm{C}$.

The sol-gel process was used to obtain oxide layers of $\mathrm{SiO}_{2}, \mathrm{TiO}_{2}, \mathrm{Al}_{2} \mathrm{O}_{3}$ in assembled microstructured components. Metal alkoxides and alcoholic solvents have been

Table. Surface enhancement factors $\mathrm{F}$ for sol/gel coatings on a metallic support, calcined at $500{ }^{\circ} \mathrm{C}(\mathrm{F}=$ by BET measured surface area / geometrical surface area).

\begin{tabular}{llllll} 
Coating & $\mathrm{Al}_{2} \mathrm{O}_{3}$ & $\mathrm{Al}_{2} \mathrm{O}_{3}-\mathrm{TiO}_{2}$ & $\mathrm{Al}_{2} \mathrm{O}_{3}-\mathrm{SiO}_{2}$ & $\mathrm{SiO}_{2}$ & $\mathrm{TiO}_{2}$ \\
\hline $\mathbf{F}, \mathbf{~ m}^{2} / \mathbf{m}^{2}$ & 430 & 100 & 193 & 255 & 74
\end{tabular}

used for the preparation of the sols. Starting from aluminum sec.-butylate (AlSB) and aluminum triisopropylate (AlTIP), $\mathrm{Al}_{2} \mathrm{O}_{3}$ films, $\mathrm{TiO}_{2}$ films made of titanium tetraisopropylate and $\mathrm{SiO}_{2}$ films made of tetraethylorthosilane as well as binary oxide films were produced [9].

It was established that the sol maturing conditions have to be selected such that the condensation rate is low. As a result, formation of a polymer structure of the oxide film is promoted, and its mechanical stability and adhesion properties are improved. Higher condensation rates tend to yield particulate sols that lead to mechanically unstable gels. Gels of this type are subject to strong shrinkage and may simply be wiped off the metal surface after drying. The low condensation rates for $\mathrm{Al}_{2} \mathrm{O}_{3}$ and $\mathrm{TiO}_{2}$ sols are achieved by adding acetyl acetone, a chelating agent. $\mathrm{SiO}_{2}$ sols were prepared based on a two step acid/base catalyst procedure [18].

The alkoxide used exerts considerable influence on the resulting oxide coating, with emphasis on the specific surface area of the coatings. The highest surface enhancement factors were found for alumina
A cross section of a stainless steel microstructured reactor with an $\mathrm{Al}_{2} \mathrm{O}_{3}$ layer is shown in Fig. 5. It is evident that the oxide layer adheres to the metal surface and does not peel off. After wet impregnation with platinum the reactor was used for the catalytic conversion of hydrogen with oxygen for a total period of more than $200 \mathrm{~h}$ [20]. Numerous temperature cycles were run and no activity was lost. This indicates a high mechanical stability of the $\mathrm{Al}_{2} \mathrm{O}_{3}$ layer on the walls of the metal microchannels.

The deposition of nanoparticles can be realized by a washcoat process or by electrophoretic deposition in an electric field.

The washcoats were based on the immobilization and the sintering of nanoparticles $(\mathrm{ZnO}$ and/or $\mathrm{CuO})$. To prepare microstructure-compatible layers of a mixture of oxides on microstructured metal foils, it was necessary to disperse the particles. The dispersion of the commercially available nanoparticles was made with a homogenizer in a mixture of a solvent (water or 2-propanol) and a polymer. The latter was necessary to obtain a stable dispersion which can be used without sedimentation. A polymer such as hydroxy ethyl cellulose 

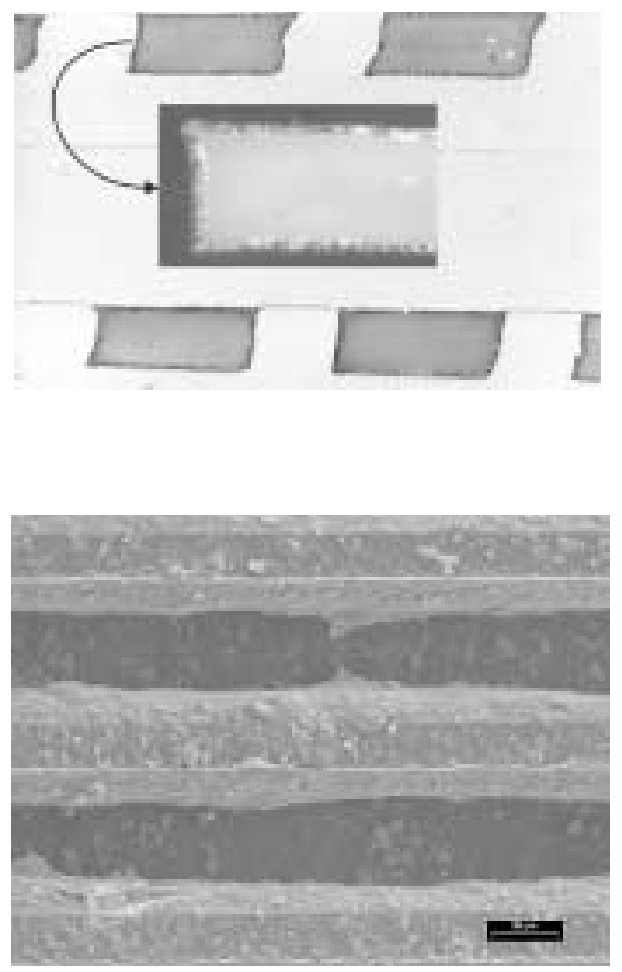

Fig. 5. Microscopic picture of a cross section of a $\mathrm{Al}_{2} \mathrm{O}_{3}$ coating made by the sol-gel process in a crossflow microchannel reactor made of stainless steel.

Fig. 6. SEM picture of a nanoparticle washcoat; pre-coated aluminum foil with channels $100 \times 100 \mu \mathrm{m}$ and $\mathrm{a}$ fin of $50 \mu \mathrm{m}$.

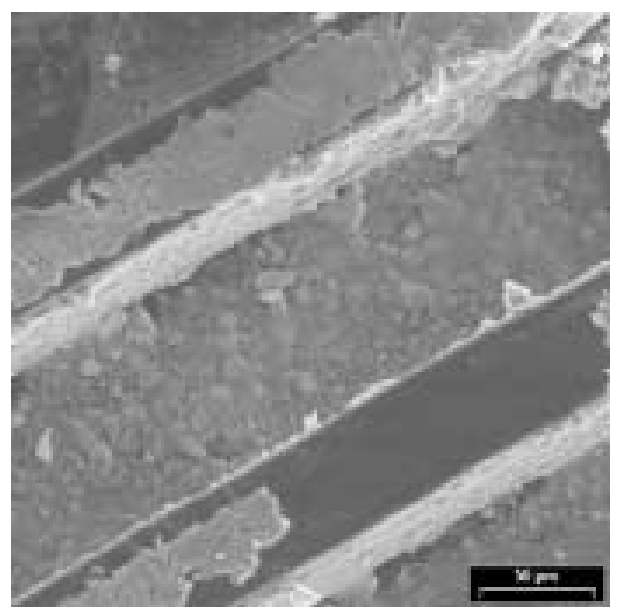

or hydroxy propyl cellulose was used. Dispersion of nanoparticles in the solvent only resulted in extremely fast agglomeration to secondary particles of several microns. The agglomeration rates is dependent on the combination of oxide, solvent and polymer as well as on the dispersion time.

Water was a favorable solvent, but the solubility of zinc oxide in deionized water might be a problem, e.g. when storing the dispersion for a longer time, for nanoparticles pre-impregnated with catalytically active substances or for mixtures of oxides. Adhesion of the nanoparticles on the metal foils was achieved by both dispersions ( $\mathrm{ZnO}$ and $\mathrm{CuO} / \mathrm{ZnO}$ ) in the non-calcined, dried state and by sintering the nanoparticles (immobilization) to a certain extent after coating and drying (see [10]).
Fig. 7. SEM picture of a nanoparticle washcoat; post-coated aluminum foil with channels $100 \times 100 \mu \mathrm{m}$ and a fin of $50 \mu \mathrm{m}$.

The sintering process influences the pore structure and the formation of intermetallic phases which, in some cases, are responsible for the catalytic behavior of the coating. The advantage of this method is that, depending on the procedure, no additional impregnation step is necessary after immobilization of the nanoparticles. The pore structure of the coating is dominated by macropores and depends on the type of the nanoparticles and the thermal treatment procedure [10][11]. Slightly oxidized or rough metal surfaces increased adhesion. The washcoating of structured single metal foils and stacked foils showed the feasibility of homogeneous pre- and post-coating (before and after assembling the foils to a reactor), which can be seen from scanning electron microscopy (see Fig. 6 and 7).
First coatings of this type have been developed and utilized for the methanolsteam reforming reaction [21].

Sintering temperatures and as well the affinity of the polymer to the oxide limit the washcoat technology. For oxides like alumina, another coating method for nanoparticles is needed. Electrophoretic deposition (EPD) represents another possibility for the deposition of $\mathrm{Al}_{2} \mathrm{O}_{3}$ nanoparticles from colloidal solutions in microchannels. Here, the mass and properties of the aluminum oxide layer in the microchannels can be influenced specifically by the parameters selected (composition and $\mathrm{pH}$, voltage density, duration).

For the experiments on electrophoretic deposition of nanoparticles, the same setup as for anodic oxidation was used. The microstructured foils were stacked in a clamping unit. For preliminary treatment, the surface of the foils was etched in the clamping unit for a period of $45 \mathrm{~min}$ using hot $96-98 \% \mathrm{H}_{2} \mathrm{SO}_{4}$. Then a dispersion of nanoparticles was pumped through the stacked microstructured foils. The distance of the anodes was $1 \mathrm{~cm}$. A voltage of $50 \mathrm{~V}$ was set. A current density of $0.5 \mathrm{~A} / \mathrm{cm}^{2}$ was observed for $20 \mathrm{~h}$. After this, the specimens were dried at $80{ }^{\circ} \mathrm{C}$ and annealed at $400{ }^{\circ} \mathrm{C}$ for $8 \mathrm{~h}$.

Studies were performed with different compositions of the $\mathrm{Al}_{2} \mathrm{O}_{3}$ nanoparticle dispersion. The solvent was water, and the $\mathrm{pH}$ of the dispersion was varied by adding oxalic acid. The viscosity of the dispersion was changed by adding dried aluminum hydroxide gel and glycerol. Using the less viscous dispersion with oxalic acid the channels were covered in a rather heterogeneous manner. Hence, no uniform layer thickness could be recorded and adhesion of the oxide layer to the metal substrate was considered to be insufficient. A relatively homogeneous layer with good adhesion properties was generated with the dispersion containing oxalic acid and $\mathrm{Al}(\mathrm{OH})_{3}$. The surface area was enlarged by $62 \mathrm{~m}^{2} / \mathrm{m}^{2}$. Under the scanning electron microscope, however, the layer exhibited relatively large cracks (Fig. 8). Layer thickness ranged between 2 and $4 \mu \mathrm{m}$.

Deposition of $\mathrm{Al}_{2} \mathrm{O}_{3}$ nanoparticles from the dispersion containing glycerol was also found to be relatively homogeneous and crack free. Following annealing, the layer density was a little higher than in case of the second dispersion. Adhesion to the metal substrate was good. Physisorption measurement yielded a surface enlargement by $102 \mathrm{~m}^{2} / \mathrm{m}^{2}$. To illustrate the boundary between the applied layer and the substrate, a transverse section was taken from the specimen, and the relative distribution of alu- 


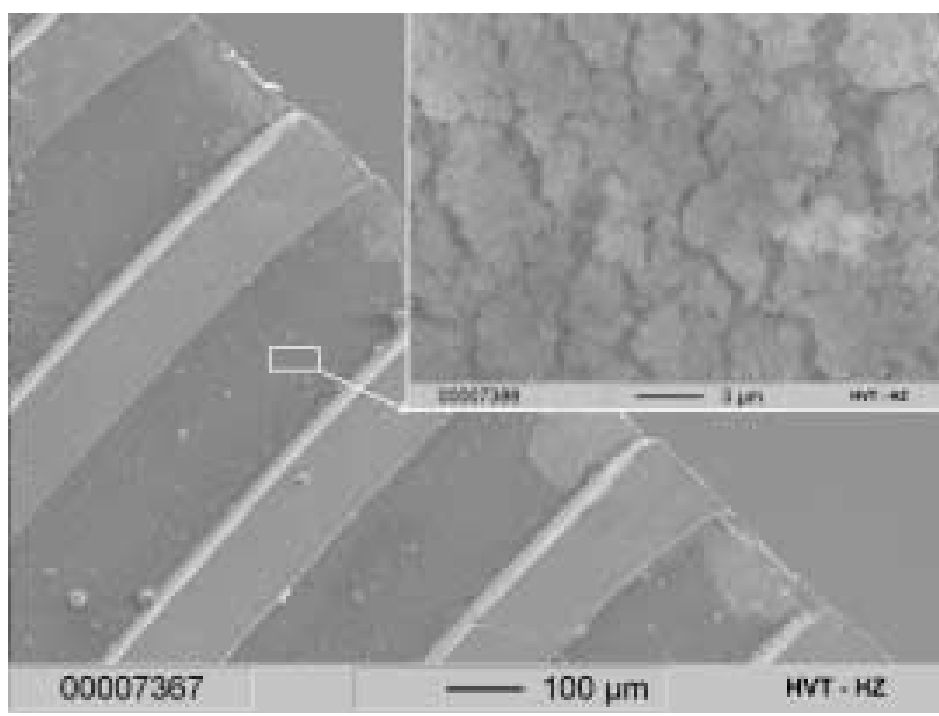

Fig. 8. SEM of an $\mathrm{Al}_{2} \mathrm{O}_{3}$ layer produced by electrophoretic deposition of nanoparticles from a dispersion containing oxalic acid and $\mathrm{Al}(\mathrm{OH})_{3}$ in the foil stack.

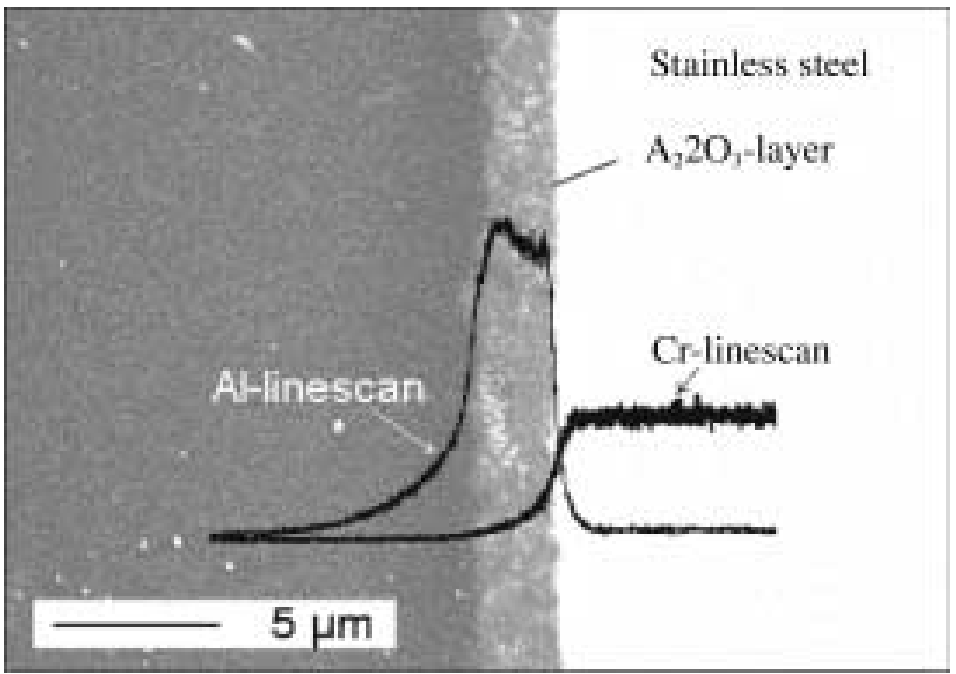

Fig. 9. SEM of a transverse section of an $\mathrm{Al}_{2} \mathrm{O}_{3}$ layer produced by electrophoretic deposition from a dispersion containing glycerol in the foil stack.

minum and chromium was determined by EDX. Fig. 9 shows that the SEM of the aluminum oxide layer and the line scans are in good agreement. Following this process, the $\mathrm{Al}_{2} \mathrm{O}_{3}$ layer has a thickness of $3 \mu \mathrm{m}$. The oxide layer is homogeneous and adheres well to the metal surface. Based on these experiments, completely manufactured microstructured reactors will be coated in a next step.

\section{Conclusions}

The methods presented here allow the production of vacuum-tight microstruc-
[1] W. Bier, W. Keller, G. Linder, D. Seidel, K. Schubert, H. Martin, Chem. Eng. Proc. 1993, 32, 33-43.

[2] W. Bier, W. Keller, G. Linder, D. Seidel, K. Schubert, Symposium Volume, DCSVol. 19, ASME, 1990, 189-197.

[3] J. Brandner, M. Fichtner, K. Schubert, Proceedings, 4th International Conference on Microreaction Technology; Proceedings, Atlanta, 6-10 March 2000, 244-249.

[4] K. Schubert, W. Bier, J. Brandner, M. Fichtner, C. Franz, G. Linder, 2nd International Conference on Microreaction Technology, Proceedings, New Orleans, 1998, 88-95.

[5] M. Janicke, H. Kestenbaum, U. Hagendorf, F. Schüth, M. Fichtner, K. Schubert, J. Catal. 2000, 191, 282-293.

[6] M. Fichtner; J. Mayer; D. Wolf, K. Schubert, Ind. Eng. Chem. Res. 2001, 40, 3475-83.

[7] G. Wiessmeier, K. Schubert, D. Hönicke, 1st International Conference on Microreaction Technology, Proceedings, Springer, 1997, 20-26.

[8] R. Wunsch, M. Fichtner, K. Schubert, 4th International Conference on Microreaction Technology, Proceedings, Atlanta, 6-10 March 2000, 481-487.

[9] K. Haas-Santo, M. Fichtner, K. Schubert, Appl. Catal. A 2001, 220, 79-92.

[10] P. Pfeifer, M. Fichtner, K. Schubert, M. Liauw, G. Emig, 3rd International Conference on Microreaction Technology; Proceedings, Frankfurt, 19-21 April 1999, 372-382.

[11] P. Pfeifer, O. Görke, K. Schubert, 6th International Conference on Microreaction Technology, Proceedings, New Orleans, 14-10 March 2002, 281-287.

[12] F. Keller, M.S. Hunter, D.L. Robinson, $J$. Electrochem. Soc. 1953, 100, 411.

[13] G. Wiessmeier, Dissertation, Universität Karlsruhe, 1996.

[14] C.J. Brinker, G.W. Scherer, 'Sol-Gel Science', Academic Press, 1990.

[15] D. Mackenzie, J. of Non-Cryst. Solids 1988, 100, 161-168.

[16] R.D. Gonzales, T. Lopez, R. Gomez, Catal. Today 1997, 35, 293-317.

[17] R. Wunsch, M. Fichtner, K. Schubert, $3 r d$ International Conference on Microreaction Technology; Proceedings, Frankfurt, 19-21 April 1999, 625-630.

[18] T.M. Harris, E.T. Knobbe, J. Mater. Sci. Lett. 1996, 15, 132-133.

[19] L.L. Murell, Catal. Today 1997, 35, 225-245.

[20] K. Haas-Santo, O. Görke, K. Schubert, J. Fiedler, H. Funke, 5th International Conference on Microreaction Technology, Proceedings, Strasbourg, 27-30 May 2001, 313-321.

[21] P. Pfeifer, K. Schubert, M. Fichtner, M.A. Liauw, G. Emig, 6th International Conference on Microreaction Technology, Proceedings, New Orleans, 14-10 March 2002, 125-130. 